\title{
Emotional Intelligence Among Adolescents
}

\author{
Sathyamurthi Karibeeran*, Shefali Mohanty \\ Social Work, Madras School of Social Work, Chennai, India \\ Email address: \\ ksm@mssw.in (S. Karibeeran) \\ ${ }^{*}$ Corresponding author

\section{To cite this article:} \\ Sathyamurthi Karibeeran, Shefali Mohanty. Emotional Intelligence Among Adolescents. Humanities and Social Sciences. \\ Vol. 7, No. 3, 2019, pp. 121-124. doi: 10.11648/j.hss.20190703.15
}

Received: May 17, 2019; Accepted: June 27, 2019; Published: July 12, 2019

\begin{abstract}
Adolescence is a period of heightened emotionality. If the adolescents cannot perceive, understand, regulate and function with their emotions it will leave indelible marks on their behaviour and personality. During adolescence (age 12 to 18 yrs), the transition from childhood to adulthood is most important. Children are becoming more independent, and begin to look at the future in terms of career, relationships, families, housing, etc. The individual wants to belong to a society and fit in. This is a major stage in development where the child has to learn the roles he will occupy as an adult. It is during this stage that the adolescent will re-examine his identity and try to find out exactly who he or she is. Emotional intelligence plays an important role in this phase. Emotional Intelligence signifies the ability to understand and manage ones as well as the others' emotions. It refers to a combination of skills these include empathy, self control, self awareness, sensitivity to the feeling of others, persistence and self motivation among others. This paper will focus on the various theories and models related to emotional intelligence and its significance. Based on the theories and models, the researcher tried to bring out a frame work which makes a difference in the emotional Intelligence of adolescents.
\end{abstract}

Keywords: Emotions, Adolescents, Emotional Intelligence and Social Work

\section{Background of the Study}

Adolescence is the time when a person acquires the ability to think further than the present, envision its implication and the future, also grasp the complexity of relationships. They encounter new experiences; unfamiliar situations often result in new and possibly intense positive and negative emotional reactions. There is a need to nurture the emotional intelligence skills for regulating their emotions and behaviour.

Peter Salovey and John Mayer were the first researchers who created the term "emotional Intelligence" in 1990. Their theory predominantly combines main ideas from the domains of intellect and emotion. The term "emotional intelligence" has generated a lot of interest since the publication of the book Emotional Intelligence by Daniel Goleman [6]. The most basic definition of emotional intelligence (E. I.) which was designed by Goleman describes it as a skill to identify and control emotions within ourselves as well as of others [4].

Peter Salovey and John Mayer defined emotional intelligence as "A form of intelligence that involves the ability to monitor one's own and other's feeling and emotions, to discriminate among them and to use this information to guide one's thinking and actions"[11]. Later they devised the definition as "The ability to perceive emotion, integrate emotion to facilitate thought, understand emotions, and to regulate emotions to promote personal growth"[8].

Reuven Bar-On [1] who helped coin the term "emotion quotient". He defines it as a individual trait which helps an individual understand oneself as well as others and it also helps the individual to adjust with the immediate surroundings thereby helping him/her in successfully coping with the environment demands. Emotional intelligence is, the ability and freedom to grow from mistrust to trust, self doubt to self- empowerment, following to leading, incompetence to competence, isolation to synergy, and despair to hope [16].

\section{Models of Emotional Intelligence}

Emotional intelligence can be studied from two perspectives such as the ability or mixed model. The ability model accentuates that emotional intelligence is a pure form 
of mental ability. On the other hand mixed models of emotional intelligence propagate a relationship between mental ability with individual persona characteristics such as optimistic outlook and wellbeing [9]. At present there is only one ability model which has been researched and proposed by John Mayer and Peter Salovey. Also there are two mixed models of emotional intelligence with different orientation. Reuven Bar-On has conceptualized and designed a mixed model which stresses that there can be co-existence of ability aspects of emotional intelligence with individual personality traits which has a direct bearing on a individual's personal welfare. On the other hand Goleman (2001) proposed a mixed model based on performance. The model encompasses an individual's abilities and personality and tries to find out its effect on performance at the workplace.

\subsection{Mayer and Salovey's (1997) Four-Branch Model of Emotional Intelligence}

Their theory predominantly combines main ideas from the areas of intellect and emotion. The intelligence theory propagates the idea that an individual having intelligence has the capability to carry out abstract reasoning. Emotion research accentuates that various emotions show different signals and meanings about relationships and states that some emotions' depictions is the same across the world [10].

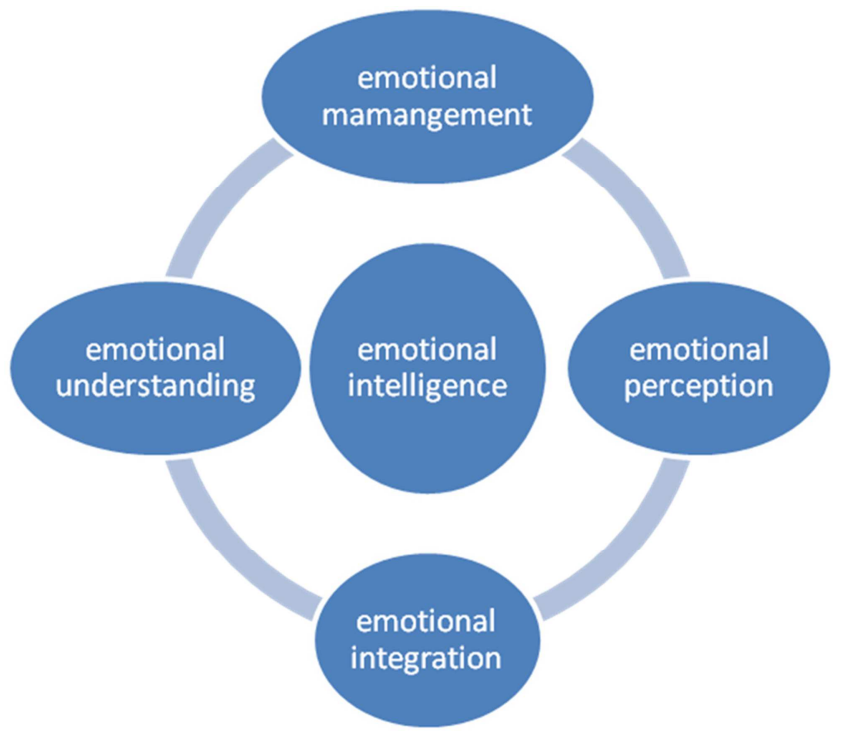

Emotional intelligence is composed of two distinct areas which are experiential and strategic.

(a) The experiential side deals with an individual's ability to gauge react and manipulate emotional cues without necessarily making meaning out of it. The first branch under the experiential side deals with emotional perception which is a skill to be aware of one's emotions and express the same in a right manner to others. It also deals with the ability to deal with the expression of honest and dishonest emotions. The second branch under the experiential side emotional assimilation is an ability to identify various emotions experienced by an individual. Once an individual is aware of it than he/she could be able to analyze the emotions that affect one's thinking process.

(b) On the other hand the strategic side deals with the understanding and management of emotions which may not be as a result of feeling or past experience. The first branch emotional understanding is the ability to identify complex emotions and the skill to identify the movements between these complex emotions. The second branch under the strategic side, emotion management is the ability to decide the usefulness of a given emotion to a given situation and thereby the skills to discard or accept it.

\subsection{Bar-On: A Mixed Model of Emotional Intelligence}

Bar On's model of emotional intelligence [1] emphasizes on the potential an individual has to perform and succeed. It accentuates on an individual's ability to solve problems and issues of a social and personal nature. The model draws attention to a number of emotional and social abilities. Predominant among them are the skills and the ability to be aware of and understand oneself and to be able to express oneself. It also includes the ability to understand others and to relate and interact with them. The model highlights the importance of the process rather than the outcome [2].

$\begin{array}{ll}\text { Components } & \text { Subcomponents } \\ \text { Intrapersonal } & \text { Self-Regard } \\ & \text { Emotional Self-Awareness } \\ & \text { Assertiveness } \\ & \text { Independence } \\ & \text { Self-Actualization } \\ & \text { Empathy } \\ & \text { Social Responsibility } \\ \text { Interpersonal } & \text { Interpersonal Relationship } \\ & \text { Reality Testing } \\ \text { Adaptability } & \text { Flexibility } \\ & \text { Problem Solving } \\ & \text { Stress Tolerance } \\ \text { Stress Management } & \text { Impulse Control } \\ & \text { Optimism } \\ \text { General Mood Components } & \text { Happiness }\end{array}$

\subsection{Goleman: A Mixed Model of Emotional Intelligence}

Goleman's model [5] helped in the identification of four main emotional intelligence constructs. The constructs are self awareness, self management, social awareness and relationship management.

(a) Self Awareness deals with an individual's ability to identify one's emotions and analyze its impact. It also deals with the ability of gut feelings while taking decisions.

(b) Self Management involves controlling one's emotions and impulses and thereby adapting to the situation and changing circumstances.

(c) Social Awareness accentuates on an individual's ability to identify, perceive and react to other's emotions while being a part of a social network. 
(d) Relationship Management talks about the ability to motivate, influence and train others when dealing with conflict.

\subsection{Trait Model of Emotional Intelligence}

Konstantinos Vasilis Petrides ("K. V. Petrides") proposed a conceptual distinction between the ability based model and a trait based model of EI and has been developing the latter over many years in numerous publications. The trait model focuses on one's perception of their emotional traits. It is "a constellation of emotional self-perceptions located at the lower levels of personality." Trait EI refers to an individual's self-perceptions of their emotional abilities. This definition of EI encompasses behavioral dispositions and self-perceived abilities and is measured by self report, as opposed to the ability based model which refers to actual abilities, which have proven highly resistant to scientific measurement. Trait EI should be investigated within a personality framework.

\section{Erikson Theory}

Erikson spoke about development of identity formation and importance of emotional expressivity. Erikson's theory of psychosocial development has eight distinct stages which assume that a crisis occurs at each stage of development. For Erikson, these crises are of a psychosocial nature because they involve psychological needs of the individual (i.e. psycho) conflicting with the needs of society (i.e. social). It is during adolescence stage that the adolescent will re-examine his identity and try to find out exactly who he or she is. Erikson suggests that two identities are involved: the sexual and the occupational. During adolescence they are emotionally vulnerable and are often unable to manage their own emotions.

\section{Theoretical Framework of the Research Study}

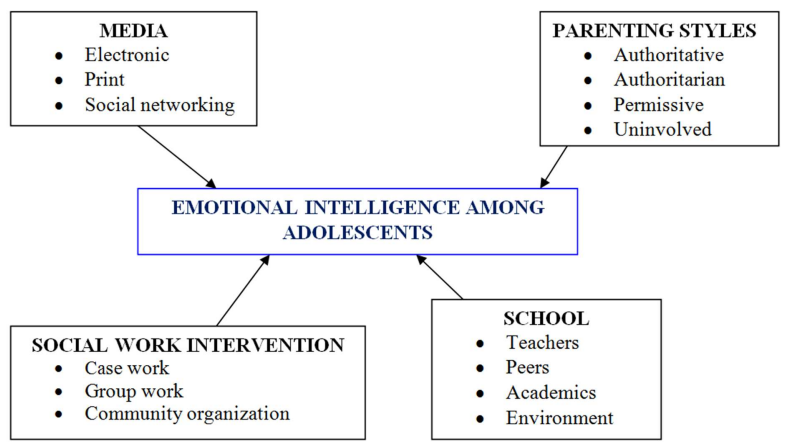

Figure 1. Shows the influence of all these factors on emotional intelligence among adolescents and with improvement in these sectors will increase the EI of the adolescents as well.

All the external factors like parenting styles of the adolescent, school environment, influence of media and using appropriate social work interventions with the help of various theories and models available related to social work can help the adolescent improve his/her capacity in dealing with emotions and feelings.

\section{Conclusion}

Emotional Intelligence helps in building ability to understand emotions and emotional knowledge; and to reflectively regulate emotions so as to promote emotional and intellectual growth. All the theories and models provide the appropriate measures to improve the emotional intelligence among adolescents. From the theories and models of emotional intelligence, the researcher could bring out a theoretical frame work which focuses on the factors that can improve emotional intelligence among adolescents. All the factors including family, school, media and proper social wok intervention can make a lot of difference in improving the emotional intelligence of the adolescents.

\section{References}

[1] Bar-On, R. (1997). Bar-One Emotional Quotient Inventory: Technical manual. Toronto: Multi-Health Systems.

[2] Bar-On, R. (2002). Bar-on emotional Quotient Inventory (EQ-I): Technical manual. Toronto, Canada: Multi-Health Systems.

[3] Bruce. E. Compas. Et.al (1995) Adolescent Development and Pathways to Problem Behavior. Annual Review of Psychology (Vanderbilt University). Page- 267-273.

[4] Goleman, D. (2001). The Emotionally Intelligent Workplace, Jossey-Bass.

[5] Goleman, D. (1998). Working with Emotional Intelligence. New York: Bantam Books.

[6] Goleman, D. (1995). Emotional Intelligence. New York: Bantam Books.

[7] K. Sathyamuthi, Child Rights: A Gender Perspective, Transcience, ISSN: 2191-1150 Vol. 2, Issue 2, pp. 59-72, 2011.

[8] Mayer, J. D. \& Salovey, P. (1997). What is emotional intelligence? In P. Salovey \& D. Sluyter (Eds.), Emotional Development and Emotional Intelligence: Implications for Educators (pp. 3-31). New York: Basic Books.

[9] Mayer, J. D., Salovey, P., \& Caruso, D. (2000). Models of Emotional Intelligence. In J. R. Sternburg (Ed.), Handbook of Intelligence (pp. 396-420). Cambridge, UK: Cambridge University Press.

[10] Mayer, J. D., Salovey, P., and Caruso, D. R. (2002). MayerSalovey-Caruso Emotional Intelligence test (MSCEIT) Users manual. Toronto, Canada: MHS Publishers.

[11] Salovey, P., \& Mayer, J. D. (1990). Emotional Intelligence. Imagination, Cognition \& Personality, 9 (3), 185-211.

[12] Sathyamurthi K (2015), Adolescent Mental Health: An Interdisciplinary Approaches, Today Publication, Chennai, ISBN: 9789381992647. 
[13] Samuel O Salami (2011), Personality and Psychological WellBeing of Adolescents: The Moderating Role of Emotional Intelligence. Social Behavior and Personality: an International Journal. 39 (6), 785-794.

[14] Sathyamurthi, K (2015) Adolescent Health: A Transdisciplinary Perspective, Today Publication, Chennai. ISBN: 978-93-81992-21-0.

[15] Sathish Kumar R. \& K. Sathaymurthi, Substance Use Disorders Among Slum Adolescents inn Chetpet, Chennai, Sacred Heart Journal of Science and Humanities, ISSN 22776613, Vol 8, Special Issue, pp. 81-87, 2015.
[16] Singh, S. K. (2007) Emotional Intelligence and organizational leadership: a gender study in Indian context", Int. J. Indian Culture and Business Management, 1 (1/2), 48-63.

[17] Sterrett, E. M., Jones, D. J., McKee, L. G., \& Kincaid, C. (2011). Supportive non-parental adults and adolescent psychosocial functioning: Using social support as a theoretical framework. American Journal of Community Psychology, 48 (3), 284-295.

[18] Wang, M. T., \& Eccles, J. S. (2012). Social support matters: Longitudinal effects of social support on three dimensions of school engagement from middle to high school. Child Development, 83 (3), 877-895. 